\title{
The Difference Between Fuzzy Trace Theory And Heuristic Theory In Risk Taking In The Context Of Financial Investment
}

\author{
Damayanti
}

\begin{abstract}
The purpose of this paper is to compare two theories, namely fuzzy trace theory and heuristic theory in the context of risk taking in financial investment decisions. Fuzzy trace theory is a global memory model developed to explain the findings that are against witha certain feeling instution about the relationship between memory and thought. Meanwhile, heuristic theory mentions that a person's behavior in making decisions with limited and short time is because of only limited informations and all of them are in the conditions of uncertainty. The heuristic theory states that the making of fast decision involves the elements of perception, memory, framing effect and the ease of processing information and overload informant's condition. The statement of the heuristic theory is not in accordance with the main principle of the fuzzy trace theory, in which a person encodes, stores, retrieves, and forgets her/his verbatim memory and gist separately and in paralel. The difference of the two theories influences the risk taking in the field of financial investment. Some factors affecting the risk taking are as the followings: (1) Financial literacy (including memory, information and investor knowledge); (2) Emotion (prioritizing her/his feeling and intuition in decision making); and (3) Risk perception (considering one's feeling and perception in making risk decisions). Based on the conceptual analysis of the factors that influence risk taking, investors need to pay attention to: (1) financial literacy; they should consider the fuzzy trace theory, (2) emotion; they should consider the heuristic theory in making decisions, (3) risk perception; they should consider the heuristic theory. It is expected that this paper is beneficial for investors and potential investors to consider some points in taking some policies suitable either with fuzzy trace theory or heuristic theory in risk taking.
\end{abstract}

Index Terms: Fuzzy trace theory, heuristic theory, risk taking and investment

\section{INTRODUCTION}

The development of financial management theories, especially financial behavior theory, has improved from time to time. The previous theories that are considered not in line with the implications of real practices have continuously developed. Though the development of financial management behavior theory is considered a quite new theory (since 1970s), it has developed by adopting many psychological theories applied in the financial management. This theory has also been used by investor, potential investor, manager, entrepreneur and people involved in financial field. One of the financial behaviour theories used by investors in making their decisions is the theories related to risk taking, those are heuristic theory and

Revised Manuscript Received on April 19, 2019.

Damayanti, Department of Management, Sekolah Tinggi Ilmu Ekonomi YPPI Rembang, Indonesia.(Email: damayanti_rahmania@yahoo.co.id) fuzzy trace theory. Heuristic theory has been known since 1973 introduced by Tversky and Kahneman, while fuzzy trace theory has been introduced by Reyna and Brainerd since 1995

This article is a conceptual discussion from the available theories that is expected to be able to develop a new theory model in the field of financial behavior. It aims to compare the two theories, i.e. fuzzy trace theory and heuristic theory in the context of risk taking in financial investment decision. The heuristic theory explains that a person's behavior in making decision in limited and short time is affected by the only limited informations, and all of them are in uncertain conditions ${ }^{\mathrm{i}}$. According to Ackert and Deaves (2010), the process of making fast decision involves the elements of perception, memory, framing effect and the ease of processing information and overload informant's condition.

Furthermore, the fuzzy trace theory also considers memory, thought, judgment, and decision making and the development in lifetime ${ }^{\mathrm{ii}}$. This theory is a memory global model developed to elaborate the findings which are against with certain institutions related to the relationship between memory and thought. Moreover, the fuzzy trace theory is a leading theory of taking decision under risk. Its main principle is that people encode, store, take, and forget memories that are marked with various levels in detail and many meanings. It involves memory, thought, judgment, and decision making and their development in lifetime.

In the fuzzy trace theory, there are two things: (1) the representation of meaning based gist that supports fuzzy intuition, and (2) superficial verbatim that is information which exactly supports an analysis. According to Reyna (2004) $)^{\mathrm{iii}}$, people form their memories in two different ways indicated by their memories that are always remembered or become the point, that is, the basic concept of understandable material which requires memory and very detail effort. The consequences, especially of risk perception, show that a person does not judge a risk in a project based on her/his past experience.

On the other hand, Tversky and Kahneman (1981) proposed that when one experiences a difficult problem to select probability or frequency, people use a number of heuristics to reduce their judgment to be simpler. According to Ackert and Deaves (2010), perception and memory are influenced by frame; as a result, financial decision is also affected by the frame. 
Hogarth $(1987)^{\mathrm{v}}$, also discussing heuristic theory, stated that the limitation of investor cognitive was in the contrary to assumption needed by optimal judgment that investor could take decision by analizing all alternative choices and risks on the market. An investor, investing in the capital market, must be able to make a prediction based on the conclusion of proofs that are contradict to one another, between an incident and another. Heath and Tversky $(1991)^{\mathrm{vi}}$ suggested that the willingness to bet on the uncertainty of an event depends not only on the estimation of possible events and the accuracy of the estimates, but also depends on one's general knowledge or understanding of the relevant context.

These two big theories become guidance in investing, especially taking risk. Risk taking behavior is investor's behavior in risk taking ${ }^{\text {vii }}$. It is shown by the investors when they allocate the number of investments in certain kinds of assets, i.e. the proportion of risk assets and number of riskfree assets. The big investors' risk taking behavior will be proved by the number of risk assets investment more than the number of risk-free assets. According to Nosic and Weber (2010), the risk taking is influenced by investors' preferences, risk perception, and their trusts. Sitkin and Pablo (1992) ${ }^{\text {viii }}$ argued that the success of decision makers to avoid from the risk will cause more risk averse, and the success of decision makers seeks the risk will make more risk seeking.

In the risk taking, if the two theories are related to each other, which theory, either fuzzy trace theory or heuristic theory, will be based on the investor's memory, information, knowledge, intuition, feeling and perception? Which theory must be adopted and beneficial for the investor in investing, whether fuzzy trace theory or heuristic theory? So, this article discusses further about those matters. It is hoped that this paper can be beneficial for the investors and the potential investors to consider a few things in making policy suitable either with fuzzy trace theory or heuristic theory in the decision of risk taking in investing. Thus, the investors, the potential investors, the managers and individuals involved in the field of the financial management can minimize the investment's risk and maximize their profits.

\section{LITERATURE REVIEW}

This article discusses the two big theories of financial behaviour, mainly of investment decision making in association with the risk (risk taking). The followings are some theories related to the article:

\section{A. Fuzzy Trace Theory}

Fuzzy trace theory is an outstanding theory of decision making under risk. The main principle of the fuzzy trace theory is that people encode, store, retrieve, and forget their memory indicated by various detailed levels and meanings. The fuzzy trace theory distinguishes between the representation of meaning based gist that supports fuzzy intuition, and the information of superficial verbatim that supports an exact analysis. It includes memory, thought, judgment, and decision taking and their development in lifetime (Reyna and Brainerd, 1995). The main principle of the fuzzy trace theory is that people encode, store, retrieve and forget their verbatim and gist memories separately and in detail.

In the fuzzy trace theory ${ }^{\mathrm{ix}}$, people form their memories in two different ways, literally indicated either by their memories which are always remembered or their gist which is the basic concept of understandable materials, requiring the memory and very detailed effort. In this theory, although people are able to form the type of their memories, they depend mainly on their gist. The consequence of risk perception shows that a person does not assess a risk in a project based on investor past experience. The fuzzy trace theory (Reyna, 2004) showed that the experience of a few violent events may obtain the same effect. This theory indicates that the risk type in evaluation becomes unimportant for a few frame works of risk perception based on the past experience from the violent events in life.

According to Reyna $(2012)^{\mathrm{x}}$, the other principle of the fuzzy trace theory is that decision making prefers to operate on simple gist taken from information. For numeric information, the differences of precision levels are taken from the measurement scale: the simplest level is categorical or nominal scale. According to Reyna (2012), constructive memory usually refers to classical ideas in which people extract a meaning from the presented information (omitting the surface shape), then use the meaning they remember to conclude what exactly occurs (that is, a memory built from the meaning). The idea of a memory scheme is almost similar, in which the memories are selectively encoded, stored and retrieved based on a prior knowledge and arranged in a scheme.

\section{B. Heuristic Theory}

Heuristicis a person's behavior in making a decision with limited and short time in which there is only limited and all are in the condition of uncertainty (Ackert and Deaves, 2010). Tversky and Kahneman (1973) ${ }^{\mathrm{xi}}$ proposed that when being faced with something difficult to assess probability or frequency, people use a number of heuristics to reduce judgment to be simpler.

According to Ackert and Deaves (2010), making fast decision involves the elements of perception, memory, framing effect dan the ease of processing information and overload information's condition. The perception is sometimes able to experience the distortion in a process because of self factors, for example, the occurrence of cognitive dissonance, i.e. a situation where a person is motivated to reduce or avoid from psychological inconsistency that often happens because the person wants to convey "a self positive self image". Memory is constructive, but the wrong information received in the past can form the memory about the incident. It is also constructive but unstable in its strength. Perception and memory are affected by a frame, so financial decision is also influenced by it.

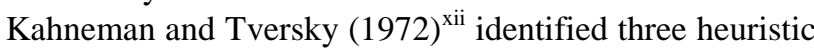
keys, those are, representative, availability and anchoring. The three keys sometimes make someone wrong in making 
decision. The hypothesis is that people predict representativenes supported in a series of studies with the subjects of both naïve and up-to-date. According to Kahneman and Tversky (1973), if an event is easy to remember it is believed to have a greater possibilty of occurring, and the belief is called availability heuristic. Kahneman and Tversky (1973) argued that a person, in a variety of situations, starts to make a decision with a belief adjusted to avalaible information to make a final decision, and the initial informant is often as the frame of a problem and this is called anchoring.

Heath and Tversky (1991) investigated an uncertainty preference alternative, called competency hypothesis, which applies to both opportunity and evidence problem. They also conveyed that the willingness to bet on the uncertainty of an event depends not only on the estimation of possible events and the accuracy of the estimates, but also depends on one's general knowledge or the understanding of the relevant context. Specifically, they proposed that the assessment of the probability of a constant person prefers betting in a context where someone considers himself knowledgeable or competent to betting in a context where the person feels stupid or lacks information. They also proposed that this attribution analysis can explain the evidence available on uncertainty preferences, whether they involve ambiguity or not.

\section{Risk Taking}

Risk taking behavior is investor's behavior in taking risks (Nosic and Weber, 2010). This can be shown by investors when they allocate the amount of investment in certain types of assets, namely the proportion of the number of risky assets and the number of risk-free assets. An investor's great risk taking behavior will be proven by the risky asset investments that are greater than the amount of investment in risk free assets. Risk taking is influenced by investor preference, risk perception, and investor's trust. The greater subjuctive financial risk attitude, the greater risk someone will take by investing in more risky assets than risk-free assets. One's high perception toward risk makes her/him tend to avoid from the risk, so s/he will choose to invest in risk assets with a small amount.

Thaler and Johnson (1990) found that decision makers would seek the risk in the profit domain if the action of seeking risk was previously successful. The same logic in law and tradition was also applied to avoid from the decision-making risks. The risk-taking tendency would depend on previous success in taking risks. According to Sitkin and Pablo (1992), the extent to which decision makers can associate the results with their actions, their success to avoid from the risk would become increasingly risk averse, and their success to seek the risk will become increasingly risk seeking.

Sitkin and Pablo (1992) argued that many researchers were interested in the factors that affected individual decision making behavior within the risk framework (Hogarth, 1987; Kahneman and Tversky, 1979). The risk behavior can be characterized by the level of risk related to the decision the investors have made. Sitkin and Pablo (1992) classified the more risky decisions as follows: (a) expected outcome is more uncertain, (b) decision objectives are more difficult to achieve, and (c) potential outcome set belongs to extreme consequences.

\section{METHODOLOGY}

This study uses conceptual theory to find a new model in developing the available theories. Financial behaviour theory in financial management has been considered as a new theory since 1980s. In relation to the risk investment decision making (risk taking), many theories are learned and developed. Therefore, this article discusses two major theories in financial behavior, those are, fuzzy trace theory and heuristic theory.

Heuristic theory and fuzzy trace theory have quite striking differences in relation to the risk taking in investment decisions. Heuristic theory explains a person's behavior in making decisions with limited and short time because there is only limited information and everything is in the condition of uncertainty. In this theory, making fast decisions involves the elements of perception, memory, framing effect and the ease of processing information and overload informant's condition. Likewise, fuzzy trace theory considers memory, thought, judgment, and decision and development in a person's lifetime. Through the discussion, this article is expected to provide a better development of science in the future.

\section{RESULT AND FINDING}

In this section, the discussion covers several parts including: 1) the differences of fuzzy trace theory and heuristic theory in risk taking, 2) the affecting factors of risk taking and the relationship between financial literacy, emotion, and risk perception of fuzzy trace theory and of heuristic theory. For more details, those can be seen in the followings:

\section{A. The differences of Fuzzy Trace Theory and Heuristic Theory in Risk Taking}

Based on the previous theoretical foundation, there are some differences between heuristic theory and fuzzy trace theory. The heuristic theory explains a person's behavior in making decisions with limited and short time because there is only limited information and everything is in the condition of uncertainty (Ackert and Deaves, 2010). According to Ackert dan Deaves (2010), making fast decisions involves the elements of perception, memory, framing effect and the ease of processing information and overload informant's condition.

Whereas the fuzzy trace theory considers memory, thought, judgment, and decision making and development in lifetime (Reyna and Brainerd, 1995). This theory is a global memory model developed to explain its findings which contradict to the certain institution in association with the relationship between memory and thought (Brainerd and Reyna, 1992). The explanation of the two theories is in the followings.

Heuristic is a person's behavior in making decisions with limited and short time and informant, and all of them are in 
the condition of uncertainty (Ackert and Deaves, 2010). Tversky and Kahneman (1973) proposed that when being faced with something difficult to assess probability or frequency, people use a number of heuristics to reduce their judgments to be simpler. According to Ackert and Deaves (2010), perception and memory are affected by frame, so financial decision is also influenced by the frame.

Hogarth and Einhorn (1981), also talking about heuristic theory, argued that cognitive limitations of investors conflict with the assumptions in which optimal judgment requires that investor is able to take decisions by analyzing all alternative choices and risks in the market. When investing, an investor in capital market is forced to be able to make predictions based on the conclusions on mutually contradictory evidence between one event and another (Hogarth, 1987). Heath and Tversky (1991) stated that the willingness to bet on the uncertainty of an event depends not only on the estimation of possible events and the accuracy of the estimates, but also depends on one's general knowledge or understanding of the relevant context.

Meanwhile, fuzzy trace theory is a leading theory of decision making under risk. The main principle of the fuzzy trace theory is that people encode, store, retrieve, and forget memories that are characterized by various levels in detail and many meanings. In this theory, it is distinguished between the representations of meaning based gist, that support fuzzy intuition, and superficial verbatim of an information, which supports proper analysis. The fuzzy trace theory includes memory, thought, judgment, and decision making and development in lifetime (Reyna and Brainerd, 1995). According to Reyna (2004), people form their memories in two different ways, literally both the memory which is indicated by their memory that is always remembered and the memory which is its core, that is a basic concept of understandable material requiring a very detailed memory and effort. The consequence of risk perception shows someone not to assess a risk in a project based on past experience.

Based on the previous research, it can be concluded that fuzzy trace theory does not approve the decision making based on past experience and risk perception, but more cautiously uses gist memory taken from the existing information. Whereas heuristic theory states that to take decisions well and quickly, investor can use the elements of perception, past experience, verbatim memory and framing effect.

This article discusses the relation between the two theories, i.e. fuzzy trace theory and heuristic theory, and risk taking in investment decision making in finance. The relationship between the two theories and risk taking is related to several things, including the factors that influence risk taking as follows: (1) financial literacy (including memory, information and investor knowledge); (2) emotion (prioritizing feeling and intuition in decision making); and (3) risk perception (considering feeling and one's perception in taking risk decision). In the fuzzy trace theory, decision making is based more on the knowledge and information, while heuristic theory prioritizes the elements of perception, past experience, and verbatim memory.

It is important to consider strategic risk in company management, because it is useful to protect the organization from the environment change of globalization. Through expectation's consideration and risk preference, managers need to compare project alternatives and make choices based on organizational resources (Fiegenbaum and Thomas, 1988) $)^{\mathrm{xiii}}$. Frank $(2008)^{\mathrm{xiv}}$ argued that managers would choose fewer negative risks if they are asked to take risks and given benefits as a consequence. Regarding to efforts to minimize the risk in decision making, an effective risk management is needed.

\section{B. Factors Affecting Risk Taking}

Before discussing the relation between risk taking and the two theories (both heuristic theory and fuzzy trace theory), it is necessary to discuss some things that influence risk taking in the behavior of financial investment.

\section{Financial literacy}

Financial literacy is information learned, organized, represented, and stored in memory ${ }^{\mathrm{xv}}$. Investors can take, use, and renew the financial literacy to create an inherent and useful property from literacy itself and make the excuses and elaboration of financial decisions. Thus, financial literacy is the measurement of the level of one's understanding about basic financial concepts and the abilities and beliefs needed to manage their own finances for short-term decisions and long-term planning, taking into account of economic events and changing conditions ${ }^{\mathrm{xvi}}$

Huston $(2010)^{\mathrm{xvii}}$ summarizes the definition of financial literacy, as the followings:

a. Financial literacy is the ability to make judgments and make effective decisions regarding to the use and management of money.

b. Personal financial literacy is the ability to read, analyze, manage, and communicate the personal financial conditions that affect her/his material welfare. This includes the ability to see financial choices, discuss financial problems without or with inconveniences, plan for the future and respond competently to life events that affect daily financial decisions, including the events in the general economy.

c. Financial literacy is the basic knowledge needed by people to survive in modern society

d. Financial literacy refers to a person's ability to understand and use financial concepts.

Bannier and Neubert $(2016)^{\text {xviii }}$ examined the financial risk taking by using standardized financial investment and advanced technology. The research results of Bannier and Neubert (2016) showed that actual and perceived financial literacy is relevant for financial risk taking, in various ways for both men and women. Sophisticated investment is significantly related to stronger perception of financial literacy for women than for men.

Aren and Zengin $(2016)^{\mathrm{xix}}$, investigated whether or not the level of financial literacy, personality characteristics and risk perception are effective in individual investment preferences consisting of deposits, foreign exchange, equity and portfolios. The study results of Aren and Zengin's (2016) showed that if the investor's financial literacy level is 
low, they will prefer deposits and foreign currencies. On the other hand, when the level of financial literacy increases, investors tend to create portfolios or buy equity. The not as the investors who prefer bank deposits. Wang $(2013)^{\mathrm{xx}}$, in the financial literacy literature, suggested two main things that could explain the relationship between financial literacy and risk taking in investment. First, good financial behavior is positively correlated with the higher levels of financial literacy (Edmiston and Gillett and Fisher, $2006)^{\mathrm{xxi}}$. Second, financial education and experience positively influence the literacy and financial behavior (Lyons et al., 2006) (xii $^{\text {. }}$

\section{Emotion}

Emotion is the response of one's feelings to an intense stimulus (Ackert and Deaves, 2010). Some common examples of emotion are anger, disgust, fear, happiness, sadness, regret and surprise. James $(1980)^{\text {xxiii }}$ stated that emotion is a change in the body directly following the perception of interesting facts, and our feelings about the same change as when it happened. The further explanation is that that there are various emotions of feelings and statements which mean that various emotion will be followed by various distinguished body movements.

Schachter and Singer (1962) $)^{\text {xxiv }}$ made a list of social emotion as the followings: first, the feelings of anger, hatred, guilt, shame, pride, admiration, and passion. Secondly, various counterfactual emotions generated by thoughts about what might happen, including: regret, joy, disappointment, happines. Third, emotion produced by thinking about what might happen such as fear and hope. Fourth, emotion produced by good or bad things that have happened such as joy and sadness. Fifth, art emotion that is triggered by the thought of other people's property such asenvy, anger, and jealousy.

According to Elster $(1998)^{\mathrm{xxv}}$, emotion can be valuable or useful. Joy and love are intrinsically pleasant, and anger can be useful to prevent unwanted things. Emotion can also be unwanted or dangerous. Shame and sadness are intrinsically pleasing, and fear can reduce a person's ability to cope with danger and also expose one's refusal to other. Therefore, it would seem natural that the question about whether people have emotion or avoid emotion can be a rational choice object. Elster (1998) argued that emotions increase decision making in two ways. First, they allow researchers to avoid from the delay of making some important decisions when there is the creation of an optimal decision decision. Second, in some cases, emotions can really help the researchers make the best decisions. In both cases, it is assumed that the decision is guided by emotion, and the reason is better than what rational thought can achieve.

\section{Risk Perception}

According to Sitkin and Weingart (1995) ${ }^{\mathrm{xxvi}}$, risk perception shows the individual's assessment of the risk's size in the uncertainty of investment returns. This indicates that risk perception is different from investors' preference for risk, as their preference for risk shows their willingness to bear the risk. The high level of risk perception shows an individual's assessment towards a very high investment risk. investors who are willing to take a risk will turn to equity

This makes the investorst end to assume that investment returns will be negative compared to the variability of actual investment results. Conversely, if the risk perception of investment is lower, investors will consume investment in certain assets that will produce more positive value. Cooper $(2011)^{\mathrm{xxvii}}$ defined the risk perception as a decision of the decision maker about the inherent risks in a situation, while risk behavior is defined as a decision with uncertain results. According to Cooper (2011), considering the inconsistent results regarding to the relationship between strategic risk perception and risk behavior, it is important to synthesize available data and determine the overall effects. From practical perceptions, it is very important to understand the effect size so that investors have a better understanding of potential risks associated with strategic planning and decision making under high risk perception. The average results of the study indicate that making a decision under perception of high risk can harm the overall business.

C. The relationship between the Factors of Financial literacy, Emotion, and Risk Perception and Fuzzy Trace Theory and Heuristic Theory in Financial Investment Decision.

Fuzzy trace theory states that although people are able to form the type of memories they show, they depend on the essence of memory. A person does not assess financial investment risk based on her/his own past experience. Whereas in heuristic theory, a person's behavior in making a decision with a limited and short time is because there is only limited information dan everything is in the condition of uncertainty. According to heuristic theory, fast decision making involves the elements of perception, memory, framing effect and the ease of processing information and overload informant's condition. The concept of heuristic theory is not in accordance with the main principle of fuzzy trace theory, in which people encode, store, retrieve, and forget verbatim memory and gist separately and in parallel. The difference between these two theories influences the risk taking in the field of financial investment. The factors that influence the risk taking consist of (1) financial literacy (including memory, information and investor knowledge); (2) emotion (prioritizing feelings and intuition in decision making); and (3) risk perception (considering one's feeling and perception in taking risk decisions). More details can be seen in the following explanation:

1. The Factor of Financial Literacy in Financial Investment Decision in the Context of Fuzzy Trace Theory and Heuristic Theory.

According to Remund (2010), financial literacy is a measurement of one's of one's understanding level about the basic financial concepts and her/his abilities and beliefs needed to manage her/his own finances for short-term decisions and long-term planning by considering economic events and continuous conditions' change. From the definition, the investors can take, use, and renew financial literacy to create inherent and useful property from literacy itself and make excuses and elaboration in financial 
decisions. There are two big differences based on heuristic theory discussed earlier. If the investors adopt heuristic theory, they make decision in limited and short time because of limited information and the condition of uncertainty. Besides, in heuristic theory, fast decision making involves the element of perception, memory, framing effect the ease of processing information and overload informant's condition. In fact, it needs ability to read, analyze, manage, and communicate the personal financial conditions that affect material welfare. The ability includes the ability to see the financial choices, discuss the financial problems with or without inconveniences, plan for the future and respond competently to life events that affect daily financial decisions, including events in the general economy. Thus, this activity requires sufficient detailed time. If the financial literacy is adjusted to heuristic theory, it doesn't suit its application for investors because in heuristic theory decision is made and assumed quickly.

The next discussion is financial literacy in relation to fuzzy trace theory. In making decision, investor requires a fairly detailed effort. This is in accordance with the opinion of Alba and Hutchinson (1987), that financial literacy is information that is learned, organized, represented, and stored in memory. The opinion is in line with fuzzy trace theory in which an investor need to consider memory, thought, judgment, and decision making and the development of her/his lifetime. She/he needs to use his memory and thoughts before taking risk decision.

Based on the discussion of the two theories, the applications with the financial literacy consideration factors in investor's risk taking decision, the writer suggests that the investors should better consider and adopt fuzzy trace theory. Before investing their funds, they should consider several things, including taking into account the risk and return they will get when investing.

2. The Factor of Emotion in Financial Investment Decision in the Context of Fuzzy Trace Theory and Heuristic Theory.

Ackert and Deaves (2010) argued that emotion is the response of one's feelings to an intense stimulus. According to Schachter and Singer (1962), emotion is classified into five, namely (1) social emotion (anger, hatred, guilt, shame, pride, pride, admiration, and passion), (2) counterfactual emotion generated by thoughts about what might happen, (3) emotion produced by thinking about what might happen, (4) emotion produced by good or bad things that have happened, (5) art emotion triggered by thoughts of other people's property. Based on emotion classification, it can be concluded that the emotion is based on one's feelings and thoughts, in this case, investors'.

Based on the differences between fuzzy trace theory and heuristic theory, the application of emotion's factor in risk decision taking (risk taking) is closer and suitable to use heuristic theory. In the heuristic theory, the investor can control their emotion better to reduce the obtained risk. They can also make fast decision by invoving the elements of perception, memory, framing effect and the ease of processing information and overload informant's condition. Because of very fast condition, the element of emotion usually influences the investors very much on decision making. They can also control their emotion to get positive advantages. Controlling emotion better will benefit the decision makers. This is in line with Elster's opinion (1998), which stated that emotion avoid from the delay of making some important and optimal decisions. Furthermore, emotion can really help the investors to make the best decision. If decision making is guided by emotion, it is expected that an investment decision will be better than what rational thinking obtains.

\section{The Factor of Risk Perception in Financial Investment} Decision in the Context of Fuzzy Trace Theory and Heuristic Theory.

Risk perception shows the individual's assessment towards the size of the risk in the uncertainty of investment returns. Risk perception is defined as the decision maker's assessment about the risk attaching in a certain situation, in this case an investment asset. It means that the high level of risk perception show that the individual's assessment towards investment risk is very high and vice versa. In managing the risk perception, an investor must be careful in making investment decisions. There are several things to consider in it, because one's perception is based more on her/his feeling and then s/he does framing to take a decision, especially of risk taking.

Based on heuristic theory, fast decision making involves the elements of perception, memory, framing effect and the ease of processing information. Related to the factor of investor's perception in making a decision, the investor tends to adopt heuristic theory. It is an account of the fact that in heuristic theory, decision making is based on the element of perception. If an investor utilizes perception amd memory in making her/his financial investment decision because of being affected by frame, her/his financial decision is also influenced by the frame. After the process of framing, it is expected that the investor will get maximum profit and obtain high investment returns. Thus, in this case, if someone involves risk perception factor in his decision investment, he should consider heuristic theory.

\section{CONCLUSION}

This article is a conceptual discussion of existing theories which is expected to be able to develop new theory model in the field of financial behaviour. The purpose of this paper is to compare two theories, namely fuzzy trace theory and heuristic theory in the context of risk taking in financial investment decision. The heuristic theory explains a person's behavior in making decision with limited and short time because of limited informations and all are in uncertain condition. In the heuristictheory, fast decision making involves the elements of perception, memory, framing effect and the ease of processing information and the condition of informan is overload. Meanwhile, fuzzy trace theory considers memory, thought, judgment, and decision making and the development in a person's lifetime.

Based on previous research, the fuzzy trace theory does not agree with decision making based on past experience 
and risk perception, but it prefer to use gist memory taken from the existing information. Likewise, the heuristic theory states that taking good and fast decision can use the elements of perception, past experience, verbatim memory and framing effect.

This article the relationship between the two theories (fuzzy trace theory and heuristic theory) and risk taking in investment decision taking in the financial field. Investment decision taking risk taking in both fuzzy trace theory and heuristic theory is in accordance with several things, including the factors affecting risk taking as the following: ((1) Financial literacy (including memory, information and investor knowledge); (2) Emotion (prioritizing feelings and intuition in decision making); and (3) Risk perception (considering one's feeling and perception in taking risk decisions). In the fuzzy trace theory, decision taking is based more on the knowledge and information, whereas in the heuristic theory, it is based on the elements of perception, past experience, and verbatim memory.

Based on the conceptual analysis of the factors that influence decision risk taking in financial investment, there are several factors to consider. First, financial literacy should consider fuzzy trace theory, because making decision requires a fairly detailed effort. Besides, financial literacy information that is learned, organized, represented, and stored in memory, and it matches the fuzzy trace theory. The second factor is emotion. Investor should consider heuristic theory in making decision. This is because the investors can control their emotion better to reduce their obtained risks in the heuristic theory. They can also make a fast decision by involving the elements of perception, memory, framing effect and the ease of processing information and the condition of informant is overload. The third factor is risk perception. The investors should consider the heuristic theory because they can use the elements of perception and memory in making their financial investment decision that is often influenced by a frame.

\section{REFERENCES}

1. Ackert, L. F., \& Deaves, R. (2010). Behavior Finance, Psychology, Decision-Making, and Market. SouthWestern Cengage Learning. 5191 Natorp Boulevard Mason, OH 45040, USA.

2. Reyna, V.F., \& Brainerd, C.J. (1995). Fuzzy Trace Theory: An Interm Synthesis. Learning and Individual Differences, 7, 1-75.

3. Reyna, V. F. (2004). How People Make Decision that Involve Risk: A Dual Processes Approach. Current Directions in Psychological Science, 13, 60-66.

4. Tversky, A., \& Kahneman, D. (1981). The Framing of Decisions and the Psychology of Choice. Science, 211, 453-458.

5. Hogart, R. (1987). Judgment and Choice. New Yok: Wiley.

6. Heath, C., \& Tversky, A. (1991). Preference and belief: Ambiguity and competence in choice under uncertainty. Journal of Risk and Uncertainty, 4, 5-28.

7. Nosic, A, \& Weber, M. (2010). How Riskily Do I invest? The Role of Risk Attitudes, Risk Perception, and Overconfidence. Decision Analysis Journal, 3 (3), 282301.

8. Sitkin, S. B., \& Pablo, A. L. (1992). Reconceptualizing The Determinants of Risk Behaviour. Academy of Management Review, 17 (1), 9-38.
9. Reyna, V. F. (2012). A New Intutionism: Meaning, Memory, and Development in Fuzzy Trace Theory. Judgment and Decision Making, 7 (3), 332-359.

10. Kahneman, D., and A. Tversky. (1973). On the psychology of prediction. Psychological Review. 80, 237-251.

11. Kahneman, D., and A. Tversky. (1972). Subjective probability: A judgement of representativeness. Cognitive Psychology, 3, 430-454.

12. Fiegenbaum, A., \& Thomas, H. (1988). Dynamic and Risk Measurement Perspectives on Bowman's RiskReturn Paradox for Strategic Management: An Empirical Study. BEBR Working Paper, 1163. College of Commerce and Business Administration University of Illinois at Urbana-Champaign.

13. Frank, L. (2008). Our Perception of Risk. Corporate Finance Review, 12, 24-26.

14. Alba, J. \& Hutchinson, J. W. (1987). Dimension of Consumer Expertise. Journal of Consumer Research, 13(4), 411-454.

15. Remund, D. L. (2010). Financial Literacy Explicated: The Case for a Clearer Definition in an Increasingly Complex Economy. The Journal of Consumer Affairs, 44 (2), 276.

16. Huston, S. J. (2010). Measuring Financial Literacy. The Journal of Consumer Affairs, 44 (2), 296-316.

17. Bannier, C. E., \& Neubert, M. (2016). Gender Differences in Financial Risk Taking: The Role of Financial Literacy and Risk Tolerance. Economics Letters, 145, 130-135.

18. Aren, S., \& Zengin, A. N. (2016). Influence of Financial Literacy and Risk Perception on Choice of Investment. Procedia Social and Behavioral Sciences, 235, 656-663.

19. Wang, A. (2009). Interplay of Investors Financial Knowledge and Risk Taking. The Journal of Behavioral Finance, 10, 204-213.

20. Edmiston, K. D., Gillett, M. C. \& Fisher. (2006). Financial Education at The Workplace, Evidence From a Survey of Federal Reserve Bank Employees. Part I: Knowledge and Behavior. Community Affairs Working Paper.

21. Lyons, A. C., Palmer, L., Jayaratne, K.S.U., \& Scherpf, E. (2006). Are We Making the Grade? A National Overview of Financial Education and Program Evaluation. Journal of Consumer Affairs, 40, 208-235.

22. James, W. (1980). The Principles of Psychology. Volume II.

23. Schachter, S., \& Singer J. E. (1962). Cognitive, Social, and Physiological determinants of Emotional State. Psychological Review, 69, 379-399.

24. Elster, J. (1998). Emotions and Economic Theory. Journal of Economic Literature, 36 (1), 47-74.

25. Sitkin, S.B. \& Weingart, L.R. (1995). Determinants of Risky Decision Making: a Test of Mediating Role of Risk Perception and Risk Propensity. Academy of Management Journal, 38, 1573-1592.

26. Cooper, T., \& Faseruk, A. (2011). Strategic Risk, Risk Perception and Risk Behaviour: Meta-Analysis. Journal of Financial Management and Analysis, 24 (2), 20-29. 


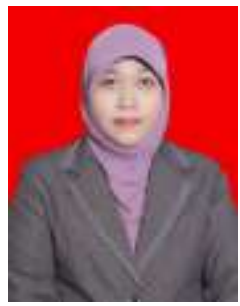

\section{AUTHORS PROFILE}

Damayanti received a bachelor's degree from the Department of Management, University Jember in 2001 and then a Master's degree in the Master of Science, Economic and Business Faculty, Gadjah Mada University in 2005. Currently studying in the doctoral program in management science at Airlangga University, Indonesia. Since 2005, she has worked as a lecturer in Departmen of Management, STIE YPPI Rembang, Indonesia. The concentration taken is financial management. You can contact via email damayanti_rahmania@yahoo.co.id 